\title{
O MUNDO DO TRABALHO E AS NOVAS COMPETÊNCIAS PROFISSIONAIS PARA O PEDAGOGO*
}

Fabiana Sena da Silva**

\section{RESUMO}

Este trabalho buscou compreender como a noção de competência, através das mudanças no mundo do trabalho, vem emergindo no cenário educacional, modificando os perfis profissionais, particularmente o do pedagogo, para enfrentar as novas demandas da sociedade. Desse modo, tratou-se de recolher e analisar a opinião de pessoas jovens, concluintes do curso de Pedagogia da Universidade Federal da Paraíba (UFPB), sobre as competências adquiridas no seu processo de formação superior para ingressar e/ou permanecer no mundo do trabalho.

Palavras-chave: competência; pedagogo.

A década de 1980 vivenciou, nos países de capitalismo avançado, profundas transformações no mundo do trabalho, fazendo surgir novos elementos como a tecnologia de ponta, a automação, a robótica e a microeletrônica, as quais invadiram o universo do trabalho. Como conseqüência dos novos elementos introduzidos no mundo do trabalho, as formas de inserção na estrutura produtiva também foram modificadas, afetando todos os profissionais e requerendo, assim, outras habilidades, conhecimentos, atitudes e capacidades para atuarem no mundo do trabalho. Dentre esses requisitos, a competência vem se configurando "como resposta às demandas do mundo do trabalho por um tipo de formação mais adequado às transformações no sistema produtivo referenciada no conceito de flexibilidade" (ARAúso, 2002, p. 98), sendo consi-

\footnotetext{
* Artigo recebido em 12/3/2006 e aprovado em 1/6/2006.

** Doutoranda na UFPB. E-mail: fabianasena@yahoo.com.br.
} 
derada essencial para o indivíduo ingressar e/ou permanecer no mundo do trabalho.

O processo de mundialização do capital implicou no surgimento de um cenário mais competitivo no mundo do trabalho, passando a se organizar através dos eixos da flexibilidade (Silva Júnior, 2002) e polivalência. Assim, os novos perfis profissionais e os modelos de formação requeridos hoje em dia com a reestruturação do mundo do trabalho podem ser expressos ainda, segundo Catani et al. (2001), na identificação de habilidades cognitivas e de competências sociais exigidas no exercício das diferentes profissões nos distintos ramos de atividade. Nesse ideário, requer que sejam repensados os perfis profissionais e os processos de formação nos âmbitos das escolas, universidades, sindicatos, empresas e organizações não-governamentais.

Dentro desse cenário, situa-se as exigências do profissional da Educação ${ }^{1}$ como compatíveis com o processo de transformação no mundo do trabalho em que nos encontramos, cujos novos cenários colocam novas questões para a Educação e, particularmente, para o curso de Pedagogia. Desse modo, são requeridas novas habilidades, mais capacidade de abstração, de atenção, um comportamento profissional mais flexível, assim como são requeridas para outros profissionais, entendendo que a competência do pedagogo não deve ser traduzida apenas por técnicas ou habilidades. Ser pedagogo nesse contexto significa, antes de tudo, ser um sujeito capaz de utilizar o seu conhecimento e a sua experiência para desenvolver-se em contextos pedagógicos, considerado o lócus de atuação dos pedagogos formados nos cursos de Pedagogia.

\section{AS TRANSFORMAÇÕES NO CONTEXTO ESCOLAR E NO PERFIL DO PEDAGOGO}

As instituições escolares também sofreram influência das transformações ocorridas no mundo do trabalho e, assim, elas acabam apresentando um comportamento semelhante ao do mundo da produção, até porque a sociedade organiza-se nos moldes do sistema vigente, ou seja, na produção da vida material dos indivíduos e nas relações que ocorrem entre eles. Como o mundo do trabalho teve que se adaptar com a introdução das novas tecnologias, com estrutura de trabalho flexível, horizontal e integrada, marcada pela exigência de profissional polivalente, competitivo e coletivo, a escola, conseqüentemente, tem a sua estrutura reorganizada, apresentando estas mesmas características. 
As mudanças no mundo do trabalho afetam diretamente a capacidade de os sistemas de ensino atenderem às necessidades da nova organização do mundo do trabalho, geradas pela introdução de novas tecnologias de informação, novos paradigmas organizacionais e novas exigências em termos de qualidade de produtos e serviços (SOAREs et al., 2003, p. 04). Essas mudanças atingem o perfil do pedagogo que, na visão das entidades representativas de formação (Ministério da Educação (MEC), Associação Nacional pela Formação de Profissionais da Educação (Anfope)) é identificado como docência, de modo que a qualidade dele pode ser verificada nos serviços que ele oferece nos processos educacionais. Considerando que a escola é, a priori, o lócus de atuação do pedagogo, pode-se perceber que o processo de trabalho tem demandado modificações ao introduzir novas tecnologias no processo ensino-aprendizagem e realizar trabalhos em equipe para a organização e condução de situações de aprendizagem, por exemplo. $\mathrm{O}$ advento das novas tecnologias fez com que alguns pedagogos mudassem - ou, pelo menos, caminhassem para mudar - a relação com os instrumentos de trabalho (o quadro-negro, o giz, o livro didático), substituindo ou utilizando, de forma paralela, o computador, os softwares e outros equipamentos tecnológicos. Acredito que eles vêm desenvolvendo habilidades cognitivas e outras competências ao utilizar as novas tecnologias para permanecer nos seus postos de trabalho.

O processo de mudanças, resultado de um novo momento histórico, político, econômico e social, é refletido por um novo modelo de produção, configurado no profissional polivalente, multifuncional e dinâmico que, na concepção de Imbernón, a formação de futuros profissionais da Educação deve estar voltada na perspectiva das mudanças para "defrontar com situações de incerteza, contextualizadas e únicas, recorrendo à "investigação como forma de decidir e de intervir" (IMBERNón, 2002, p. 39) nas situações surpreendentes presentes no cotidiano do pedagogo.

O pedagogo é o "profissional que age em diversas instâncias da prática educativa, direta ou indiretamente ligada à organização e aos processos de transmissão e assimilação de saberes e modos de ação" (LiBÂNEO, 1999, p. 44), o que lhe possibilita atuar tanto no campo da ação pedagógica escolar como no campo da ação pedagógica extra-escolar. Esse profissional tem na sua formação - o curso de Pedagogia - o vínculo com diferentes áreas, como a Sociologia, Economia, Lingüística, Psicologia, 
História, Filosofia ${ }^{2}$, possibilitando além de refletir a sua prática pedagógica, buscar alternativas extra-escolares para trabalhar em processos de capacitação em serviço e de intervenção pedagógica em empresas, indústrias, turismo, hospitais, televisão, rádio etc. Existem dois tipos de pedagogos $^{3}$, conforme Libâneo (1999): o primeiro tipo configura os professores de todos os níveis de ensino e os demais profissionais (administradores escolares, supervisores e orientadores escolares), enquanto o segundo tipo é composto por especialistas dedicados a atividades de pesquisa, documentação, formação profissional, gestão de sistemas escolares, coordenação pedagógica, animação sociocultural, formação continuada em empresas, escolas e outras instituições. A divisão da formação nos tipos profissionais está prevista na proposta de reforma formulada pelo MEC (2005) em separar as licenciaturas dos bacharelados de todas as áreas. As licenciaturas se destinarão a formar professores para atuar na educação infantil e nos anos iniciais do ensino fundamental nos cursos normais superiores, podendo também se realizar em cursos de pedagogia, quando oferecidos pelas universidades e centros universitários. ${ }^{4}$ Já os bacharelados serão cursos que habilitarão o candidato a exercer uma profissão de nível superior.

Levando em conta que a atuação do pedagogo não se restringe à escola, por existir a ação pedagógica em múltiplos setores da sociedade, ele não pode ser mais visto apenas como profissional habilitado somente à docência para atuar na escola, pois a ação pedagógica não pode ser reduzida ao trabalho escolar e docente (LiBÂNeo, 1999). As diferentes práticas educativas acontecem em diversos lugares e em várias situações, conduzindo às atividades de cunho pedagógico no bairro, nos pequenos grupos, nas relações de vizinhança, ou seja, nos postos de trabalho, nos meios de comunicação e em instituições não escolares. Tais práticas implicam na modificação também da tarefa do pedagogo, bem como na sua identidade profissional, pois para ele se abre um leque de atuação cada vez maior fora dos âmbitos escolares, o qual deve ser considerado pelas agências de formação (escolas, universidades, curso normal superior, institutos superiores de educação).

Isto posto, as características presentes no mundo da produção podem ser verificadas e aplicadas na função do pedagogo, quando eles são instigados a realizar planejamento em equipes, compartilhar saberes, dialogar sobre as suas dificuldades, fazer dinâmicas de grupo entre si e serem flexíveis. Há a exigência de pedagogos com características, habili- 
dades, aptidões, conhecimentos e interesses esperados de um profissional que atenda a nova realidade, tendo em vista a sua atividade, o contexto social, tecnológico e cultural em que atuam para a continuação na formação de profissionais com essas peculiaridades.

\section{COMPETÊNCIA: O NOVO REQUISITO DO MUNDO DO TRABALHO}

Nos últimos anos, o termo competência ocupa lugar de destaque nos discursos e documentos dos diferentes agentes e instituições sociais no mundo, fazendo parte do cotidiano de alguns protagonistas sociais, como empresários, profissionais liberais, governos, instituições educativas etc., envolvidos nos processos de mudança e transformação em curso. Freqüentemente, esse conceito polissêmico, na grande maioria das vezes, é empregado como equivalente e sinônimo de qualificação. Entretanto, parte-se do pressuposto, expresso nas idéias de Ramos (2002), Manfredi (1998) e Dubar (1998), que qualificação e competência denotam sentidos e intenções diferentes.

A passagem da centralidade de qualificação para o de competência, aqui apresentada de modo breve, pode ser observada através das dimensões conceitual e social apontadas por Schwartz e apropriadas por Ramos (2002). A dimensão conceitual da qualificação refere-se à formação e ao diploma, portanto, ao nível de domínio dos conceitos e do conhecimento, expedido por um certificado. Entendida também por Aranha (2000, p. 272) como o conjunto de habilidades e conhecimentos adquiridos pelo profissional para exercer uma atividade profissional, sendo um processo que se realiza como construção social. Para se colocar em condições de exercer a atividade do trabalho, o profissional qualifica-se em espaços diversificados como escola, universidade, empresa, sindicato e associação, revertendo-se em um importante capital em todo uso profissional. Para a obtenção de um emprego, o diploma configura-se como importante requisito. Nesse sentido, questiona-se: o diploma atesta que houve uma qualificação, mas será que pode assegurar uma competência profissional? E quanto à qualificação, ela garante a competência?

Com as novas características tendenciais, como a flexibilização da produção e a reestruturação das ocupações, a qualificação sofreu questionamentos sobre a sua adequação e a sua suficiência como estruturante das relações de produção e dos códigos de acesso e permanência no mercado de trabalho, de modo que essas características tendenciais 
passam a ser compreendidas não mais pela qualificação, mas pela competência, visto ser a fornecedora da flexibilidade exigida atualmente pelo mundo do trabalho em geral e a promotora do reconhecimento e da valorização dos aspectos subjetivos, não-formais e implícitos da qualificação (RAmos, 2002).

Múltiplos, portanto, são os significados da noção de competência, e, neste trabalho, compreende-se competência como a demonstração, dentro de situações concretas, de domínio de saberes e de habilidades, apreendidos e aprendidos, promovendo a capacidade de inovar com autonomia nas decisões e ações.

De acordo com os jovens concluintes do curso de Pedagogia da UFPB, a competência tem o significado voltado para ação, relacionado com a prática, ou seja, é preciso fazer algo para que a competência apareça. Assim, pode-se verificar que a maioria dos jovens ${ }^{1}$ afirmou que competência:

é a responsabilidade de saber fazer aquilo que declaramos que sabemos fazer; $(\mathrm{J} 1)^{2}$

é executar bem o que se faz através de um conhecimento aprofundado da área de atuação; (J2)

é realizar atividades que atendam aquela realidade; (J3)

é a capacidade que o indivíduo tem e adquire para desempenhar serviços, tarefas. Mas é um processo inacabado, é um contínuo aprendizado. (J4)

Os verbos usados para expressar o que é competência são: fazer, realizar, desempenhar, os quais dão idéia de movimento. Isso significa que os jovens acreditam que a competência está relacionada à ação. Ramalho et al. (2003, p. 78) esclarece que "a competência não é uma ação que podemos definir como uma atuação, mas sim um potencial de intervenção que pode se manifestar no contexto real", sendo caracterizada como uma potencialidade de ação, ou seja, o indivíduo mostra-se competente quando demonstra a mobilização dos saberes apreendidos e aprendidos com autonomia para aplicar em situações concretas.

As definições dadas pelos alunos concluintes possibilitam refletir sobre a questão do profissional competente. Para um jovem concluinte ser competente é "um profissional dinâmico, que saiba direcionar a teoria que possui em ações concretas no dia-a-dia. Saber resolver 
"pepinos", com seriedade e principalmente segurança" (J4, grifo da entrevistada). Esta opinião é pensada para além do fazer, da ação, como mencionaram os jovens anteriores, centrando na capacidade de mobilizar o saber, ou a teoria, para resolver problemas e enfrentar os imprevistos na situação de trabalho. Não basta apenas executar, assim como possuir somente saberes disciplinares escolares ou técnico-profissionais, mas, sobretudo, movimentar os saberes para o contexto da ação.

Já para outra jovem é:

um profissional competente requer ainda mais profissionalismo, buscando novas formas de informações, sendo maleável e se adequando à globalização, se reciclando e nunca parando no tempo, esperando o tempo passar, e achando que já aprendeu tudo que tinha para aprender. (J7)

Esta opinião está compatível com a orientação do modelo de produção toyotista, cujo profissional deva atender o novo cenário, tendo em vista a sua atividade, o contexto social, tecnológico e cultural em que atua a partir da flexibilidade, sinônimo de maleável, termo usado pela jovem para caracterizar um profissional competente. Nas falas das jovens J7 e J4, pode-se detectar uma operacionalização da definição do profissional competente, baseada na ação de um profissional capaz de articular o conhecimento para a resolução de conflitos, problemas no ambiente de trabalho. Quanto aos demais jovens, percebe-se, nas falas deles, que não conseguiram expressar vínculo com a questão anterior, ao emitirem respostas que não imprimem consistência no seu conteúdo. A pesquisa também detectou que, para outros alunos, um profissional competente é aquele que:

Está dentro das normas exigidas pelo mercado. (J2)

Aquele que desenvolve com seriedade suas funções, buscando sempre refletir sobre sua prática. (J3)

O que realiza o trabalho com dedicação. (J5)

É aquele capaz de realizar uma atividade de forma eficaz e eficiente. (J8)

Aquele que consegue desempenhar suas atividades com valores necessários para o desenvolvimento da profissão. (J9) 
Estas respostas levam a questionar o que os jovens estão chamando de normas, seriedade, dedicação, valores, eficaz e eficiente. Por não apresentarem uma definição a respeito desses termos, torna-se obscuro o entendimento de um profissional competente por usar palavras vazias, podendo ser exemplificada com a resposta de J9 que apresentou uma definição para profissional competente, mas não mencionou a definição de competência. Por outro lado, possibilita também pensar que as definições dadas por J3, J5 e J8 podem refletir características do indivíduo. Assim, pode-se inferir que a competência reflete a capacidade da pessoa. Uma determinada pessoa só será competente se desenvolver com seriedade as suas funções, ou se realizar de forma eficaz e eficiente as suas atividades, ou, ainda, se realizar com dedicação suas tarefas. Já a opinião de $\mathrm{J} 2$ está situada nas regulamentações do mercado de trabalho, embora não tenha mencionado quais são as normas.

Ao serem questionados sobre as suas competências, a maioria dos jovens considera-se competente, mesmo não fazendo relação com a questão anterior, a exemplo de J4: "Sim, porque a competência é o espelho da comunicação". Quanto a J3, ela prefere que as pessoas lhe atribuam a qualidade de competente. Para J9, ela não se considera competente por não atuar na área de Pedagogia, mas "para o que desejo fazer e/ou executar profissionalmente, sei que sou competente", de modo que ela não expressou o que deseja fazer. Percebe-se nestas falas que estas jovens não se consideram profissionais competentes e nem pedagogas competentes. Mas o que falta para elas se tornarem profissionais competentes ou pedagogas competentes? Assim, J4 acha que, para ser uma profissional mais competente, precisará ser dinâmica, séria, crítica, saber trabalhar em equipe, estar sempre estudando, pesquisando novas metodologias, participar de encontros e palestras. Outra entrevistada (J9) continuou sendo redundante, não demonstrando uma definição clara e precisa para ser um profissional competente, de tal modo afirmando: "Desenvolver habilidades que supram as necessidades do exercício da profissão". Isso leva a fazer o seguinte questionamento: quais seriam essas habilidades? Quais seriam as necessidades da profissão que devem ser supridas? E que profissão seria essa? A do pedagogo? O que o exercício da profissão de pedagogo exige? Na minha percepção, a profissão do pedagogo exige competências voltadas para o ensino e a gestão, fundamentalmente, aprimorando e desenvolvendo metodologias de ensino e conteúdo programático, bem como buscando a organização 
do trabalho pedagógico escolar, no planejamento, na execução e avaliação de propostas pedagógicas da escola.

Os documentos do curso de Pedagogia da UFPB, a Resolução 13/96 e a proposta do projeto político do curso de Pedagogia e a Associação Nacional pela Formação de Profissionais da Educação (Anfope), através da sua proposta de diretrizes curriculares para o curso de Pedagogia, não apresentam uma noção de competência. Apenas os dois últimos documentos mencionam inúmeras competências necessárias para um profissional da educação ser docente e/ou gestor.

Compreende-se que a apropriação da competência pelos profissionais configura-se em uma tomada de responsabilidade dos próprios profissionais e não delegadas por outrem. Ou seja, a competência requer a mobilização de recursos para resolver situações que surgem no cotidiano da profissão. Mas, para se chegar à competência é preciso observar o processo de formação, pois se compreende que a competência é oriunda da qualificação, embora não esteja restrita a ela. A construção de competências exige mais que saberes, demandando a aplicação desses saberes apreendidos no processo de qualificação. Em conseqüência, a construção de competência põe em discussão os conteúdos da formação, os métodos de transmissão e a certificação pelo diploma, sendo a ligação entre a dimensão conceitual da qualificação e das competências que é questionada (Roche apud Ramos, 2002, p. 62).

Verifica-se que a competência realiza-se apenas nas situações concretas, uma vez que elas só podem ser comprovadas na prática (RAmalho, et al., 2003; PerRenoud, 1999, 2000 e 2001; Machado, 2001). Nesse caso, como se materializam as situações concretas? Perrenoud (1999, p. 28), elaborando uma reflexão acerca das competências e situações, constata que a vida coloca às pessoas, amiúde, frente a situações novas, lançando mão das aquisições e da experiência, entre a inovação e a repetição, de acordo com a idade, condição e escolhas. Perrenoud continua a sua reflexão declarando que a vida das pessoas não é tão estereotipada para que a cada dia se tenha precisamente os mesmo gestos para fazer, as mesmas decisões para tomar, os mesmo problemas para resolver. Ao mesmo tempo, não é tão anárquica ou mutante que se deva, constantemente, reinventar tudo. As pessoas, de modo geral, buscam encontrar um equilíbrio, o qual varia de uma pessoa ou fase do ciclo de vida para outra, entre as respostas rotineiras para situações semelhantes e as respostas a serem construídas para enfrentar 
obstáculos novos. Assim, esse autor defende a tese de que as competências permitem enfrentar conjuntos de situações.

Assim, a reflexão sobre competência à luz dos autores supracitados, que envolve uma relação estreita entre conhecimento e inteligência, constitui uma tentativa de compreensão da reconfiguração dos espaços e tempos do lócus do trabalho, revitalizando o significado do papel dos profissionais em um cenário onde as idéias de conhecimento e de formação encontram-se definitivamente imbricadas.

\section{O MODELO DE COMPETÊNCIAS NO MUNDO EDUCACIONAL}

Os modelos teóricos e operacionais de competências, com seus requisitos ou indicadores adotados no mundo da produção, também se inserem no campo da educação. As exigências da maior competitividade, produtividade e de inovação do sistema produtivo se estende ao sistema educacional. Até o início da década de 1980, com a mudança de paradigma no mundo do trabalho, as condutas das pessoas eram pautadas na referência ao passado e na tradição, para as tomadas de decisão relativas à mobilização dos recursos. Nas escolas, as práticas seguiam o mesmo critério, o ensino tradicional era o que prevalecia. Entretanto, a partir das duas últimas décadas do século $\mathrm{XX}$ e dos primeiros anos do início do $\mathrm{XXI}$, as tradicionais formas de ver o mundo foram desmontadas, já não se tratando mais de adotar soluções acabadas, mas de inventar, em cada situação, novas possibilidades, em um mundo em transformação com idas e vindas, cortes e rupturas.

A noção de competência, atribuída à capacidade do profissional da Educação para transmitir os conteúdos de acordo com estabelecido, é substituída pela competência baseada em prover as pessoas para que lidem com as situações de incerteza, de transformação, de resolução de problemas que são postas no mundo do trabalho. Alessandrini (2001, p. 160) ajuda-nos a refletir sobre a introdução da competência no cenário da educação, quando afirma:

Há um novo paradigma vigente diante de uma sociedade que busca nas respostas [...] [Pois], muitas vezes deparamo-nos com dilemas que nos desafiam a agir de forma inusitada até mesmo para nossa própria maneira de ser e de fazer. Percebemos que a fórmula mágica de antigamente não se adequa àquilo que precisamos resolver. Notamos 
que algo precisa ser diferente, ou melhor, que precisamos mudar nossa maneira de responder às questões que a vida nos apresenta.

Na Europa já se iniciava, nos anos 80 , um processo de reformulação dos sistemas nacionais de formação profissional e de formação geral, tendo como base o enfoque das competências, com o objetivo não só de adequar a formação profissional aos requisitos da nova divisão internacional do trabalho, como também de unificar os sistemas de formação profissional, tornando possível a disponibilidade e transferibilidade dos profissionais, os quais passariam a ter livre circulação no mercado de trabalho setorial, intra-setorial, nacional e internacional, nesta etapa do capitalismo desregulado, aberto e sem fronteiras. Em outras palavras, essas reformulações demonstram a estreita relação do mundo do trabalho com o mundo escolar ou do ensino profissionalizante.

No Brasil, a introdução da noção de competência ocorreu a partir das reformas educacionais nos anos 90 , realizadas sob a orientação e o apoio financeiro de organismos internacionais (Banco Internacional de Desenvolvimento, Banco Interamericano de Desenvolvimento, Unesco, Organização Internacional do Trabalho). Essa reforma tem como objetivo "articular e subordinar a produção educacional às necessidades estabelecidas pelo mundo do trabalho e a necessidade de estabelecer mecanismos de controle e avaliação da qualidade dos serviços educacionais" (Deluiz, 2001, p. 6). A partir da década de 1990, a noção de competência é apresentada como central na organização curricular no Brasil, sendo considerada como novo elemento da educação. A adoção das competências no currículo das instituições de ensino superior (IES) para a formação de profissionais tem como objetivo a organização do processo de ensino e aprendizagem em função da mobilização das competências, exigindo aos cursos das IES a idéia de um perfil profissional projetado, visto que o uso da noção de competência pelas IES seria capaz de promover o encontro entre trabalho e formação.

Ao considerar que a relação entre o mundo do trabalho e as IES estaria mais estreita, por meio da formação voltada para as competências, reflito a respeito de como o curso de Pedagogia da UFPB propicia conhecimento aos seus alunos para atuarem no mundo do trabalho. Assim, nas afirmações de alguns jovens entrevistados, as informações contidas nos livros, textos, jornais e na internet trazidas pelos professores servem como instrumentos para promover o encontro entre trabalho e formação. 
Para uma jovem, o curso de Pedagogia é muito critico, o que possibilita o profissional de ter uma visão ampla sobre o mundo do trabalho (J2). Há outros jovens que afirmaram justamente o contrário. O curso não oferece conhecimento para atuar no mundo do trabalho, deveria realizar atividades de articulação entre a teoria e a prática, de modo a trazer o conhecimento da realidade da profissão do pedagogo para a sala de aula. Para J4, os professores necessitam enxergar a realidade do pedagogo na atualidade.

De acordo com Deluiz (2001, p. 10), existem diferentes concepções que permeiam o modelo de competências, sinalizando para a existência de várias matrizes teórico-conceituais que orientam a identificação, definição e construção de competências para a formulação e a organização do currículo. Para esta autora, essas matrizes estão ancoradas em modelos epistemológicos que as fundamentam e podem ser identificadas como a matriz condutivista ou behavorista, funcionalista, construtivista e críticoemancipatória. ${ }^{3}$

Para a organização do currículo através do modelo das competências, faz-se necessário algumas "indicações gerais", segundo Deluiz (2001, p. 10):

investigação dos processos de trabalho para a identificação de perfis profissionais de conclusão; definição dos blocos de competências profissionais básicas, gerais e específicas relacionados aos perfis identificados; desenho da estrutura do currículo, em geral flexível e modularizado; definição dos itinerários profissionais com critérios de acesso aos módulos e ao curso; definição das estratégias de aprendizagem - prática pedagógica interdisciplinar e contextualizada, processo centrado na aprendizagem do aluno, individualização dos percursos de formação, construção significativa do conhecimento, seleção de situações de aprendizagem baseadas na pedagogia de projetos e situações-problema; e definição do processo de avaliação da aprendizagem.

Tais indicações, segundo Deluiz (2001), configurar-se-ão como abstratas, sem um significado mais explícito e concreto, caso os pedagogos e outros profissionais na área da Educação não considerarem as formas como serão implementadas estes indicadores e suas relações com as matrizes teórico-conceituais.

Para o desenvolvimento de novas competências nos indivíduos para ingressar ou permanecer no mundo do trabalho, no âmbito do ensino 
superior, este precisará atender às demandas econômicas e de emprego, ou seja, preparar para o trabalho e para formas alternativas de trabalho, visando à adaptação dos profissionais às complexas condições de exercício profissional no mundo do trabalho. Mas, ao mesmo tempo, não deve estar submisso às suas exigências. Assim, o ensino superior deve possibilitar ao profissional ser capaz de pensar, criar, desenvolver iniciativa para resolver problemas e outros requisitos tácitos, com metodologias de ensino-aprendizagem voltadas para situações reais.

No processo de ensino-aprendizagem em situações reais para o desenvolvimento de competências, busquei apoio em Perrenoud (1999, 2000 e 2001). A noção de competência, no contexto escolar, é compreendida por este autor $(1999$, p. 7$)$, como "uma capacidade de agir eficazmente em um determinado tipo e situação, apoiada em conhecimentos, mas sem limitar-se a eles". Perrenoud parte do princípio que há um "movimento da profissão" (PerRenOud, 2000, p. 14), considerando que o ofício docente é mutável, cujas transformações passam pela emergência de novas competências ou pela acentuação das competências reconhecidas. Desse modo, Perrenoud elenca dez competências para o professor por serem coerentes com a redefinição das políticas educativas, com o novo papel dos professores, com a evolução das didáticas e com a evolução dos programas escolares, a saber: organizar e dirigir situações de aprendizagem; administrar a progressão das aprendizagens; conceber e fazer evoluir os dispositivos de diferenciação; envolver os alunos em suas aprendizagens e em seu trabalho; trabalhar em equipe; participar da administração da escola; informar e envolver os pais; utilizar as novas tecnologias; enfrentar os deveres e os dilemas éticos da profissão e administrar sua própria formação contínua. Embora reconheçamos que muitas dessas competências são clássicas para o exercício do professor, acredito que Perrenoud elaborou esse referencial com caráter provisório, mas sendo um meio de relembrar caminhos conhecidos e trilhar alguns outros" (PerRenoud, 2000, p. 12).

A introdução dessas competências na formação do professor é vista pelo referido autor como imprescindível para o profissional desenvolver uma prática reflexiva com ênfase no que está mudando no cenário profissional, ou seja, uma necessidade para o desempenho do ofício de professor nos tempos atuais. Na opinião de alguns jovens entrevistados (J1, J7 e J6), para um profissional ser competente é necessário "buscar mais informações". Há que se perguntar: o que 
eles fariam com as informações obtidas? Será que para ser um profissional mais competente é preciso que se tenha muitas informações? Compreendo que não é uma questão de informação, mas do que fazer com a informação. Anteriormente, foi mencionado que a competência é muito mais do que a aquisição de informações, podendo se configurar em saberes, mas, sobretudo, a mobilização desses saberes para resolver situações concretas. Portanto, é necessário saber como aplicar as informações obtidas. Não se pretende aqui mostrar que os conteúdos devam ser rejeitados, assim como as disciplinas e os saberes, mas afirmar que a abordagem por competências acentua a implementação dos saberes e conteúdos.

Para o desenvolvimento de competências, na perspectiva de Alessandrini (2001), é preciso que envolva a construção de esquemas por parte do professor e do aluno. Porém, é necessário que o professor construa seus próprios esquemas de conhecimento para propiciar que seu aluno também os construa. Isso possibilitará que o professor aprenda a observar a evolução do processo, aplicando tal conhecimento na compreensão do caminho trilhado por seus alunos (AlEsSANDRINI, 2001, p. 166). Com efeito, as competências são formadas passo a passo, segundo um processo de construção contínuo, o qual ocorre a partir de um diálogo interior, representado pelas relações intrapessoais, assim como pelas relações interpessoais. As competências profissionais estão presentes em um professor reflexivo, capaz de avaliar e de se auto-avaliar de acordo com uma postura crítica. Como conclui Alessandrini (2001, p. 166), as competências refletem-se nas tomadas de decisões, no que diz respeito à escolha de estratégias adaptadas aos objetivos educacionais estabelecidos e às exigências éticas da profissão.

\section{CONSIDERAÇÕES FINAIS}

Desde a década de 1990, acentuam-se as mudanças no mundo do trabalho que vão exigir do profissional da Educação novas competências para ensinar e gerir. Atualmente, não mais se destaca a necessidade de desenvolvimento de competências técnicas de um professor, mas sim de competências necessárias para o trabalho em grupo, a criatividade, a autonomia, a disciplina etc. Para isso, o pedagogo deve ser preparado para criar em seus alunos o que dele deve ser esperado para a ocupação, mais tarde, no mundo do trabalho. 
A formação do pedagogo pensada sob a forma de definição de competências a partir apenas do savoir-faire de determinada tarefa faz com que a formação passe a ser direcionada pelas necessidades do mundo do trabalho, buscando soluções eficientistas e imediatistas para a formação. Dessa forma, o pedagogo estará apto a formar nos indivíduos hábitos necessários à nova organização social, que tem apenas na competição seu elemento privilegiado em face das novas exigências do mundo do trabalho, sem, contudo, ser capaz de mobilizar os saberes para enfrentar determinadas situações. Mas, se a formação for além do domínio das competências técnicas (necessárias, imprescindíveis), será preciso direcionar essa formação para a construção de um profissional crítico, questionador e capaz de mobilizar os saberes para enfrentar diversos tipos de situações postas pelo mundo do trabalho.

Assim, verificou-se que a noção de competência ou, melhor, a opinião e autopercepção sobre ser um profissional competente foi compreendida pela maioria dos jovens como algo individualizado, estando centrada no indivíduo, e não no curso, como era esperado. Aliás, os jovens concluintes assumiram que nenhum curso garantia a competência, reforçando a observação de que a competência é algo subjetivo e adquirido através de esforço pessoal, principalmente quando não existe um sentimento de identificação profissional, parâmetros capazes de avaliar as competências do profissional em sua atuação no mundo do trabalho, e uma proposta política do curso ou da profissão que reflita ou expresse as aspirações e necessidades coletivas da categoria profissional. Falta ao curso de Pedagogia um projeto político pedagógico capaz de expressar a identidade do profissional, sobretudo do jovem concluinte inexperiente da prática profissional concreta. Este foi o segundo ponto conclusivo.

\section{ABSTRACT}

This study tried to understand, amid changes in the world of work, the idea of competence as it manifests itself in the educational scenario, with its modification of professional profiles, particularly that of the educator, as s/he faces the new demands of society. With this in mind, young undergraduates finishing their degree course in Pedagogy at the Universidade Federal de Paraíba (UFPB) were interviewed. Their opinions about the competence acquired throughout the process of their $3^{\text {rd }}$ level formation to enable them to join or remain on in the world of the work, were collected and analyzed.

Key-words: competence; educator. 


\section{NOTAS}

1. Chamo de profissionais da Educação aqueles que são formados para atuar no campo da ação pedagógica escolar, como os professores do ensino público e privado; os especialistas da ação educativa escolar; especialistas em atividades pedagógicas para-escolares, atuando em órgãos públicos, privados e públicos não-estatais.

2. Essas áreas de conhecimento, como um lugar diferenciado com identidade e problemática próprias, abarcam a compreensão de questões que envolvem problemáticas no campo da Educação, conforme Libâneo (1999).

3. Esses dois tipos de pedagogos abrem uma discussão antiga para a dicotomia entre os pedagogos que pensam e os que executam, ou melhor, entre teoria e prática na formação, mas não se configura objeto de interesse dessa investigação tal discussão, embora reconheça a necessidade de formar pedagogos para atuar em diversos espaços para além da escola.

4. As Licenciaturas formarão também professores para as séries finais do Ensino Fundamental e no Ensino Médio, ocorrendo nas Licenciaturas das áreas específicas do conhecimento - Licenciatura em Física, em Matemática, em Geografia, etc.

5. Os demais jovens apresentaram, em suas falas, respostas semelhantes a estas.

6. Os entrevistados serão identificados por $\mathrm{J}$ (jovem) 1 ...9, sempre que se utilizar as opiniões fornecidas nas entrevistas por eles, evitando-se, assim, identificações pessoais.

7. Para saber mais a respeito desses modelos epistemológicos, consultar Deluiz (2001).

\section{REFERÊNCIAS}

ALESSANDRINI, C. D. O desenvolvimento de competências e a participação pessoal na construção de um novo modelo educacional. In: PERRENOUD, P., THURLER, M. G. et al. As competências para ensinar no século XXI: a formação dos professores e o desafio da avaliação. Porto Alegre: Artes Médicas Sul, 2001.

ARANHA, A. Qualificação do trabalhador. Dicionário da educação profissional: núcleo de estudos sobre trabalho e educação. Belo Horizonte: Fidalgo e Machado, 2000.

ARAÚJO, R. Saber tácito. Dicionário da educação profissional: núcleo de estudos sobre trabalho e educação. Belo Horizonte: Fidalgo e Machado, 2000. 
CATANI, A. M. et al. Política educacional, mudanças no mundo do trabalho e reforma curricular dos cursos de graduação no Brasil. Educação e Sociedade. v. 22, n. 75, Campinas, 2001.

DELUIZ, N. O modelo de competências profissionais no mundo do trabalho e na educação: implicações para o currículo. Boletim Técnico do Senac, Rio de Janeiro, v. 27, n. 3, set/dez 2001.

DUBAR, C. A sociologia do trabalho frente à qualificação e à competência. Educação e Sociedade. v. 19, n. 64, Campinas, set. 1998.

IMBERNÓN, F. Formação docente profissional: formar-se para a mudança e a incerteza. 3. ed. São Paulo: Cortez, 2002. (Coleção Questões da Nossa Época, v. 77)

LIBÂNEO, J. C. Pedagogia e pedagogos, para quê? 2. ed. São Paulo: Cortez, 1999.

MACHADO, N. J. Sobre a idéia de competência. In: As competências para ensinar no século XXI: a formação dos professores e o desafio da avaliação. Porto Alegre: Artes Médicas Sul, 2001.

MANFRENDI, S. M. Trabalho, qualificação e competência profissional das dimensões conceituais e políticas. Educação e Sociedade, v. 19, n. 64, Campinas, set. 1998 .

PERRENOUD, P. Construir as competências desde a escola. Trad. Bruno Charles Magne. Porto Alegre: Artes Médicas Sul, 1999.

Dez novas competências para ensinar. Trad. Patrícia Chittoni Ramos. Porto Alegre: Artes Médicas Sul, 2000.

PERRENOUD, P.; THURLER, M. G. et al. As competências para ensinar no século XXI: a formação dos professores e o desafio da avaliação. Trad. Cláudia Schilling e Fátima Murad. Porto Alegre: Artes Médicas Sul, 2001.

RAMALHO, B. L.; NUÑEZ, I. B.; GAUTHIER, C. Formar o professor, profissionalizar o ensino: perspectivas e desafios. Porto Alegre: Sulina, 2003.

RAMOS, M. N. A pedagogia das competências: autonomia ou adaptação? 2. ed. Cortez Editora. São Paulo, 2002.

SILVA JR., J. dos R. Tendências do ensino superior diante da atual reestruturação do processo produtivo no Brasil. São Paulo: [s.n], 2002.

SOARES, S.; CARVALHO, L.; KIPNIS, B. Os jovens adultos de 18 a 25 anos: retrato de uma dívida da política educacional. IPEA. Texto para discussão n. 954. Rio de Janeiro, junho, 2003.

UNIVERSIDADE FEDERAL DA PARAÍBA. Consepe. Resolução n. 13/1996. Reestrutura o Currículo do Curso de Graduação em Pedagogia, do Centro de 
Educação, do Campus I, com base na Resolução n. 2/69, do CFE, e dá outras providências. João Pessoa, 1996. Disponível em: www.ufpb.br/sods. 